\title{
Building a Strong Foundation: Mentoring Programs for Novice Tenure-Track Librarians in Academic Libraries
}

\section{Mandi Goodsett and Andrew Walsh}

\begin{abstract}
Increasingly, new librarians graduate to face a world of changing technology and new ways of interacting with information. The anxiety of this shifting environment is compounded for tenure-track librarians who must also meet scholarship and instruction requirements that may be unfamiliar to them. One way that librarians can navigate the transition to tenure-track professional positions is to participate in mentoring programs for new academic librarians. This study examines the effectiveness of mentoring programs for novice tenure-track libraries in a variety of library settings, and provides examples of successful academic library mentoring programs already in place with the intent that librarians use the data and findings to construct or improve their own library mentoring programs.
\end{abstract}

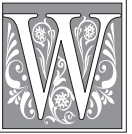

ith the introduction of new technologies and ways of interacting with information, librarianship faces increasingly rapid change and new demands. ${ }^{1}$ It is in these unsteady circumstances that novice academic librarians find themselves, often facing the uncertainties of the new information environment with little or no guidance beyond their initial training. The positions that new librarians acquire may also be more challenging or require more responsibilities than originally anticipated upon graduation from library school. ${ }^{2}$ All of these factors contribute to a growing need for libraries to establish mentoring programs for new librarians. Examining the mentoring programs for new librarians in place at academic libraries, the reception of these programs by mentors and mentees, and the elements of successful programs can provide rich data for the improvement or implementation of mentoring programs at academic libraries of varying sizes, goals, and needs.

According to the SAGE Handbook of Mentoring and Coaching in Education, mentorships are "critically supportive, nurturing relationships that actively promote learning, socialization, and identity transformations within their work environments, organizations, and professions." 3 Many examples of strong mentoring programs in the workplace exist, and most involve the sharing of knowledge and experience, a willingness to listen and nurture, and a mutual desire for the mentee's success. ${ }^{4}$ In Kathy Kram's theory of mentoring roles and responsibilities, one of the most recognized among mentorship

Mandi Goodsett is Performing Arts \& Humanities Librarian at Cleveland State University; e-mail: a.goodsett@csuohio.edu. Andrew Walsh is Instruction and Assessment Librarian at Sinclair Community College; e-mail: andrew.walsh662@sinclair.edu. (2015 Mandi Goodsett and Andrew Walsh, AttributionNonCommercial (http://creativecommons.org/licenses/by-nc/3.0/) CC BY-NC. 
literature, there are two aspects of a successful mentoring relationship: functions that enhance the mentee's career goals, and functions that are psychosocial, such as emotional support and role-modeling behavior. ${ }^{5}$ For a successful mentoring relationship to exist, the mentoring program must then do more than orient the mentee to his or her new responsibilities and work culture-it must also provide the mentee with a supportive, nurturing setting as he or she adapts to those new duties and institutional environment.

Mentoring is often confused with coaching, but the two kinds of relationships differ. While both involve nurturing, trust, and learning, the goal of coaching is not to develop the mentee at the career level. ${ }^{6}$ Coaching focuses on addressing performance issues and is often initiated out of a need for the learner to attain or improve a work-related skill. Mentoring, on the other hand, involves the exchange of institutional knowledge, discussions of core values, and planning for long-term career goals-a much larger scope than a coaching relationship. Coaching is not mentoring, but sometimes effective mentoring relationships need moments of coaching for the mentee to gain the confidence and skills to reach the career goals of the mentoring relationship.?

There is evidence of the benefits of mentoring relationships throughout the literature, with authors citing such benefits for mentees as improved institutional integration, stronger job performance, more professional development opportunities, and betterestablished career goals. ${ }^{8}$ The benefits extend beyond mentees to the mentors themselves, and to their institutions overall. Mentors are given a chance to strengthen their leadership skills and their relationship with new colleagues, reflect on their own career goals and expectations, and gain exposure to changes in the profession that new librarians may bring from graduate school or other libraries. ${ }^{9}$ Institutions themselves invest quite a bit in hiring a new employee, especially a tenure-track one, so a mentoring program can do much to nurture that investment and ensure that new employees are satisfied in their positions. ${ }^{10}$ In addition to improved retention and integration of new employees, mentoring programs can enhance communication and productivity in the workplace. ${ }^{11}$ These benefits contribute to a consensus in the literature that mentoring programs have been worth the expense in time and money to institutions that have implemented them.

Despite the generally agreed-upon benefits of mentoring programs, the literature points to several potential hurdles in the mentoring process. Without a general environment of engagement in the program, it can lose steam and support, rendering it ineffective. ${ }^{12}$ It can also be detrimental to force a mentoring relationship upon two participants against their will. The mentee and mentor will learn little if either participant is not invested in the relationship. ${ }^{13}$ Mentoring can also be ineffective if the matching of the mentor and mentee is not carefully executed. Mismatches between mentor and mentee can lead to a lack of commitment, communication problems, or even negative feelings between the pair. ${ }^{14}$ However, a carefully planned and implemented mentoring program can successfully avoid these hurdles before they become a problem.

The presence of a mentoring program can be especially beneficial for a mentee in the first stages of his or her career, when the individual is forming an "occupational identity" and envisioning long-term career goals. ${ }^{15}$ It is in this stage that newly-hired librarians who are in their first tenure-track positions find themselves, facing new challenges of scholarship, teaching, and service.

\section{Literature Review}

The use of mentoring programs in libraries is not a new idea, nor is the idea of focusing mentoring efforts on new tenure-track librarians. ${ }^{16}$ Many previous studies describe specific academic library mentoring programs that focus on promotion and tenure expectations of service, teaching, and scholarship. ${ }^{17}$ In a recent study of mentoring pro- 
grams in Canadian academic libraries, Harrington and Marshall explore informal and formal mentoring programs in Canadian academic libraries and, more specifically, the attitudes felt toward these programs by MLIS students, MLIS graduates, new librarians, more experienced librarians, and library administration. The authors conclude that what new MLIS students expect in terms of mentoring and guidance after graduation does not match what administrative librarians feel should be available to new librarians. ${ }^{18}$ However, the majority of study participants agreed that mentoring programs that focus on psychosocial support, career help, and role modeling are effective and important to the development of new librarians.

In another expansive study on mentorship in academic libraries, Freedman examines the mentoring programs of a variety of higher education institutions, providing data about the mentoring activities, mentoring model types, and commencement dates for each mentoring program. ${ }^{19}$ She argues that, although the profession of librarianship is changing, making mentorship programs increasingly popular, the programs themselves are also changing to suit the varying needs of librarians at many stages of professional development. A mentoring program, she concludes, can bring about a general atmosphere of productivity and engagement for a library.

Osif also confirms the value of mentoring programs for academic libraries by examining successful mentoring programs in a variety of academic libraries and highlighting uniquely effective elements of each. ${ }^{20}$ Mentoring activities such as the creation of a website or bibliography for mentees, implementation of a forum for mentor-mentee discussion, day-long workshops, and regularly-written reports or reflections are mentioned as methods that might be adopted in mentoring programs at other libraries. It is made clear that no set of activities or structural elements can create the perfect mentoring program and that much is dependent on the library itself. However, being aware of the decisions of others in creating mentoring programs can be beneficial in tailoring the best program for each library's needs and goals.

One difficulty for all tenure-track librarians, not just novice ones, is the ongoing issue of defining their tenure responsibilities as compared to non-librarian faculty, who often have very different job duties. ${ }^{21}$ The weight of service and scholarship for librarians may differ by institution, and these responsibilities, combined with everyday duties, can lead to anxiety and strain for new tenure-track librarians. ${ }^{22}$ In a case study example at Regent University, Lee presents her own experiences mentoring new librarians as part of a committee to review dossier drafts and provide guidance as new librarians tackled grants and other large projects. The novice librarians described in the study often expressed a feeling of anxiety in their efforts to meet promotion requirements on top of other work. However, with mentoring, these librarians went on to achieve promotion despite heavy workloads. ${ }^{23}$

Traditionally, a mentoring relationship consists of a single mentor with more professional experience guiding and supporting a single mentee in an effort to overcome professional challenges. ${ }^{24}$ However, many nontraditional mentoring models have been developed, some of which, in various situations, have proven to be more successful.

In group mentoring, all participants act as mentors to one another in a peer-mentor relationship, and no single participant is assumed to have more valuable knowledge to share than any other. ${ }^{25}$ Stony Brook University Libraries have adopted a retreat format for the their junior-level librarian mentoring program that reflects this peer-mentoring model. ${ }^{26}$ The retreat format allows mentees to build a more personal connection with their peers and speak more freely with more experienced, higher-level colleagues. ${ }^{27}$ The University of Kansas Libraries also adopted group mentoring in 2005 in direct response to a lack of available mentors for traditional one-on-one mentoring. The group mentoring model, which included a series of formal sessions, was successful enough 
that the libraries have continued using this model even after the shortage of mentors ended. ${ }^{28}$ Other libraries that have adopted peer-mentoring models include those of Wake Forest University and City University of New York (CUNY). ${ }^{29}$

Wake Forest University also used reverse mentoring as part of their peer-mentoring program.$^{30}$ In reverse mentoring, a younger or newly graduated librarian is paired with an older or more experienced librarian. The younger librarian then can share his or her knowledge of emerging technology, new models of practice, and library gadgets and software, while the older, more experienced librarian shares knowledge of the institutional culture and how to navigate the professional world. The reverse-mentoring model allows the new librarian to feel like a valuable contributor to the relationship and provides opportunities for professional development of both librarians.

The University of Idaho library, in its study of traditional and peer-mentoring models, chose something different for their librarians: the community of practice. This model involves uniting a group of employees with a range of experience levels and providing members with opportunities to share ideas, ask for research advice, critique one another's work, and form collaborative bonds. The success of this kind of mentoring model depends on formalized elements like an internal leader, a platform through which to share ideas, and specific activities that retain the momentum of the group. For libraries that struggle to find enough mentors or mentees to form traditional mentoring pairs, a community of practice offers a strong alternative. ${ }^{31}$

A relatively new mentoring structure is the Resource Team Model. Here, mentoring relationships are formed with up to three (traditional) mentors at the same time. ${ }^{32}$ Librarians from California State University, Long Beach use this model for their mentoring program and discuss the importance of caution in choosing team members and a leader for each resource group, as well as the need for assessment measures to ensure the continued success of the team collaboration. The program, the authors admit, is still evolving, but initial feedback is positive and the costs of time and money are reported to be worthwhile.

Some libraries begin with one model and adopt another as the needs of their employees become more apparent. In a closer look at a particularly successful mentoring program, "And Mentoring for All: The KU Libraries' Experience" describes a program initiated in 1998 for pre-tenure librarians at the University of Kansas Libraries. ${ }^{33}$ The librarians involved in creating this program describe the process of fostering an attitude of acceptance for the program in the administration and library staff, forming a committee, pairing mentors and mentees, assessing the program, and making changes to it over time. The program's transformation from a traditional one-on-one, single, long-term mentoring relationship to something more flexible and varied reflects a trend among library mentoring programs, and the University of Kansas Libraries, like many others, recognize that there is still much to discover about the best structure of a mentoring program at an academic library.

The experiences of specific libraries in mentoring novice tenure-track librarians are valuable, but they only provide isolated perspectives from specific libraries. Questions remain, such as: How should mentoring programs be configured based on library needs? Should they be more formalized or casual? Should mentors and mentees be trained and, if so, how? This study attempts to fill a gap in the literature about mentoring new tenure-track librarians by taking a broader look at the perspectives of mentors, mentees, and program facilitators across a wide variety of academic libraries that employ tenure-track librarians. The characteristics of academic libraries vary greatly by financial and administrative support, staff size, and turnover of librarians, so presenting the experiences of many different academic libraries allows librarians to tailor a successful mentoring program more easily to their libraries' unique situations. 


\section{Research Questions}

This study endeavors to address the potential need for mentoring programs for novice tenure-track librarians as they navigate rapidly changing information environments with the added responsibilities associated with seeking tenure and promotion. Through survey data and interview responses, this study attempts to answer the following research questions:

1. What role does a mentoring program play in preparing novice tenure-track librarians to meet the requirements of tenure?

2. What critical elements define successful mentoring programs for novice tenuretrack librarians in various academic library environments?

\section{Methods}

Data collection for this study was conducted in two ways: a web-based survey distributed to librarians and phone interviews with survey participants who volunteered their contact information. The study was submitted to and accepted by the Institutional Review Board at Georgia Southwestern State University, where one of the authors was then employed.

\section{Survey Data Collection}

The authors first designed a 19-question online survey to collect data about mentoring programs in academic libraries. Once the study received IRB approval, the survey was hosted via a secure link using Survey Monkey online software. Participants were solicited using two professional e-mail lists, the ILI listserv (an information literacy and instruction list for librarians) and the NMRT listserv (the list for the American Libraries Association New Members Round Table). There were no restrictions to participation. Of the 19 survey questions relating to academic library mentoring programs, seven allowed for open responses. At the end of the survey, subjects were given the opportunity to volunteer to be interviewed, either by e-mail or phone, by submitting an e-mail address. After responses were collected, the survey data were coded and analyzed with Survey Monkey. For a list of all survey questions, please see "Survey Questions" in appendix A.

\section{Interview Data Collection}

Following completion of the survey, the authors conducted phone interviews with survey participants to learn more about individual experiences with mentoring programs and obtain more detailed information relating to the study's research questions. Participants for the interviews were chosen from those survey respondents who volunteered their e-mail addresses. Of those who voluntarily left contact information, interviewees were chosen based on the presence of mentoring programs for tenuretrack librarians at their institutions. The authors contacted 12 potential interviewees and conducted interviews with the six who responded. Prospective interviewees were given an interview consent form to sign and return, after which a 30-50-minute phone conversation was scheduled. One interview was conducted via Skype and five were conducted by phone between the dates of January 14 and January 19, 2014. The Skype interviews were recorded using the Pamela call recording application, and the phone interviews were recorded using Google Voice or a digital voice recorder.

Interview questions focused on the mentoring program in place at the interviewee's library, including its history, goals, activities, and effectiveness. Interviewees were also asked basic questions about their library and the role they play in the mentoring program. After the interviews were completed, the interviewer transcribed and anonymized the data and then deleted the original recordings. The authors then coded the 
interview data and identified common themes. For a full list of interview questions, please see "Interview Questions" in appendix B.

\section{Findings}

\section{Survey Data}

Of the 283 participants in the survey, 55 percent $(n=156)$ indicated that they were librarians working in an academic library (43\% did not respond). Over a third (35\%, $\mathrm{n}=100$ ) identified as a librarian with two or more years of experience at his/her current institution, 12 percent $(n=34)$ identified as a newly hired librarian at his/her current institution with professional experience at another library, 7 percent $(n=19)$ identified as a newly hired librarian in his/her first professional library position, 3 percent $(n=7)$ identified as either a library school student, an unemployed library school graduate, or a retired librarian, and 43 percent $(n=122)$ did not respond. There were relatively few respondents who identified as new librarians (18\%); however, the data about mentoring programs described by the many experienced librarians provide valuable insight into what an ideal program would look like for new librarians.

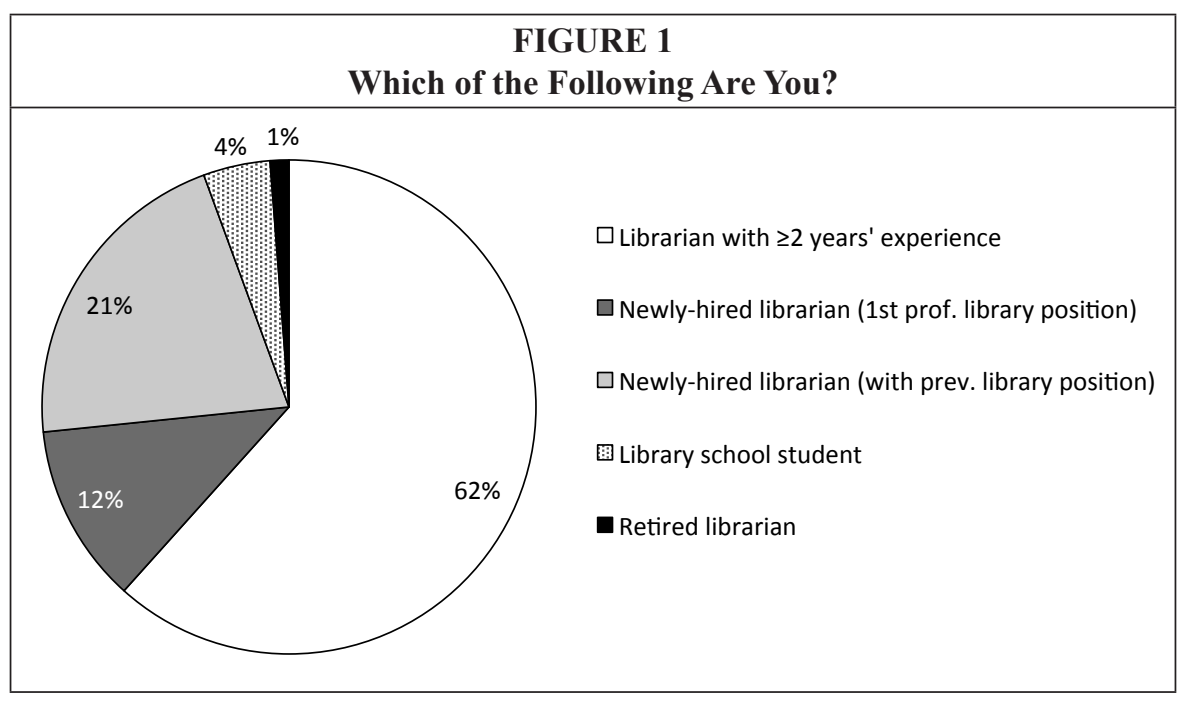

More than half $(60 \%, n=96)$ of participants who responded indicated that their library did not have a formal or informal mentoring program beyond new librarian training. Of those librarians who identified as new librarians (either with previous professional experience or without), 38 percent $(n=20)$ had a formal or informal mentoring program offered at their library. Of those participants who did have a mentoring program of some kind (including experienced and inexperienced librarians), 88 percent $(n=59)$ participated in the program, indicating that, where institutions have mentoring programs, librarians show a high rate of participation.

This study attempts to measure the effectiveness of mentoring programs at academic libraries that focus on meeting tenure requirements. Of those librarians who participated in their mentoring program, 80 percent $(n=47)$ indicated that they were tenured or tenure-track librarians, and 61 percent $(n=36)$ indicated they were in their first tenure-track positions. Requirements for tenure were collected in open responses and analysis revealed that most involve an aspect of service (whether institutional or com- 


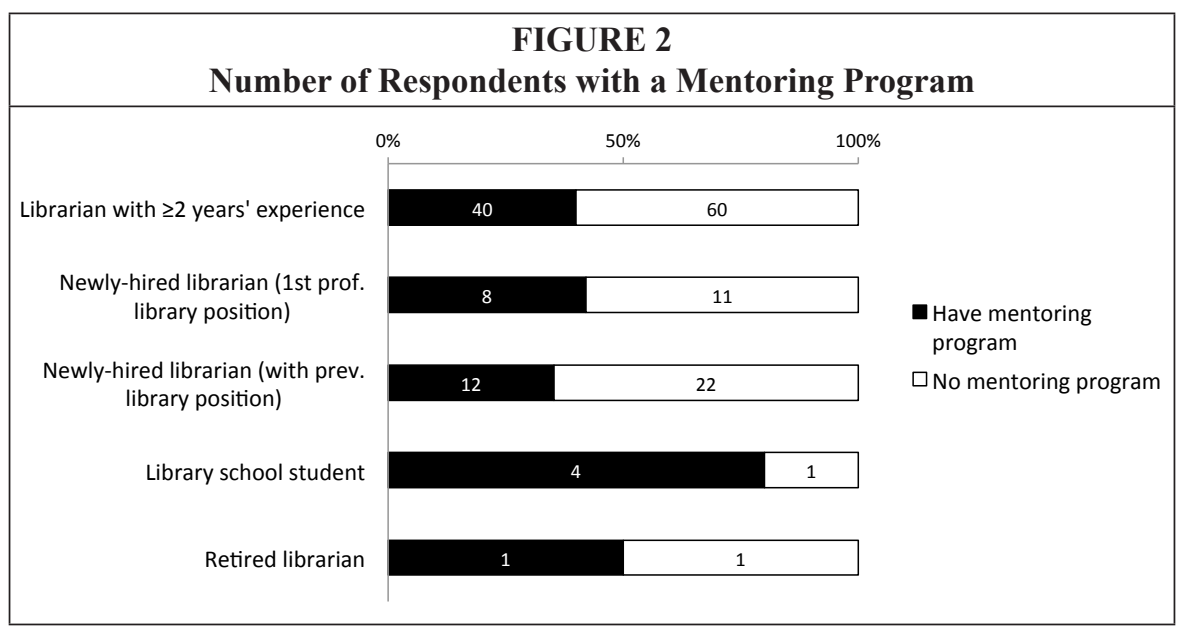

munity), professional development in the form of publications, presentations, and/or participation in professional organizations, and something often called "librarianship," which involved the fulfillment of job-related duties. Some also required excellence in teaching (usually instead of "librarianship") or the earning of a second master's degree.

Looking at the specific areas involved in the mentoring programs of respondents, most focus on promotion and tenure (70\%). Many also address issues of institutional culture, publishing, and research, which are, again, relevant to promotion and tenure. Few provide guidance with IRB policies or grant writing.

The specific activities included in mentoring programs of those who responded ranged from regular meetings, e-mail correspondence, and a general policy of open communication; mentioned least frequently were cooperative projects, panel presentations, and the use of social media interaction. The most common basis for the mentoring relationship seems to be one of one-on-one conversation, not larger guided programs like workshops and panel presentations.

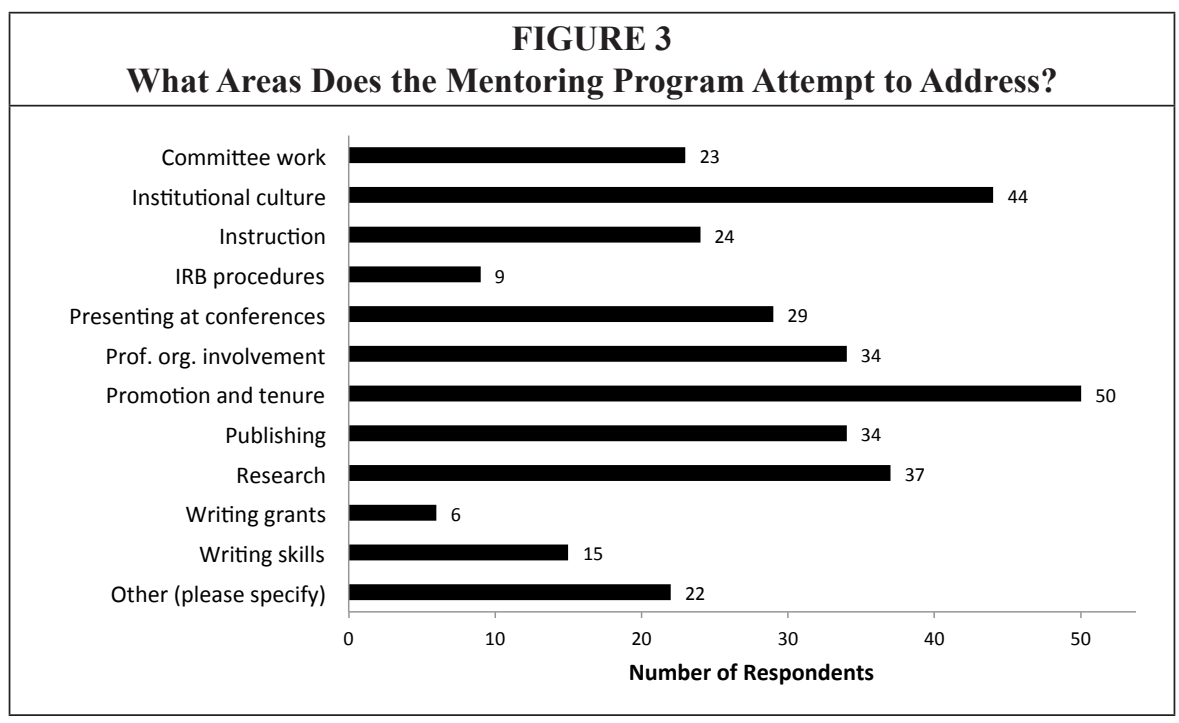




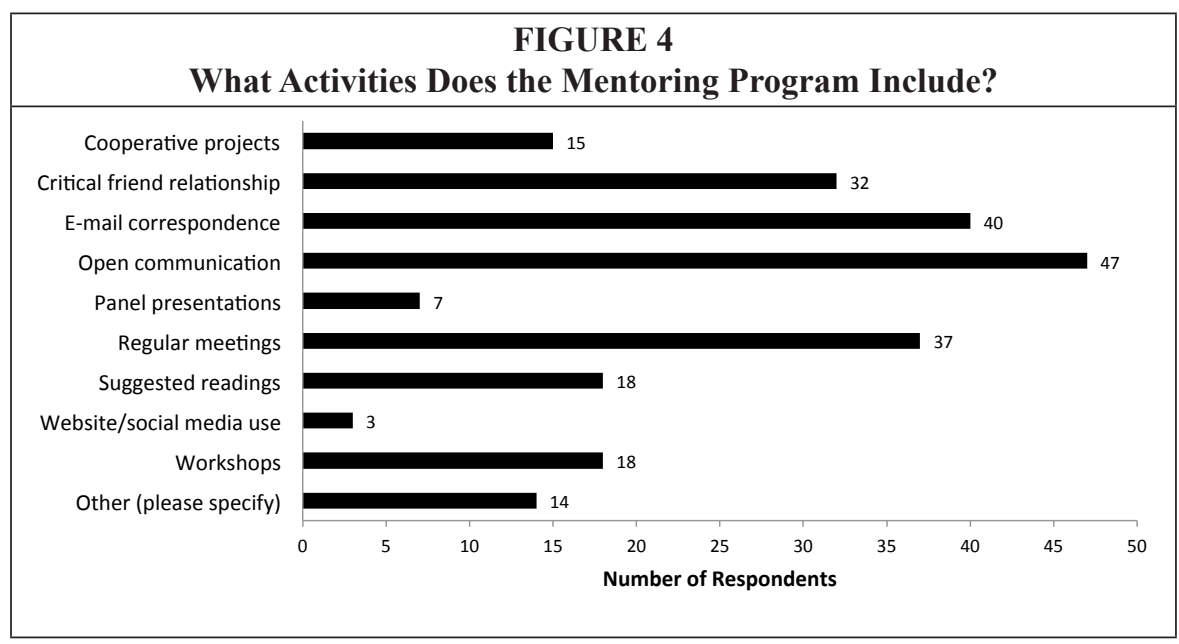

Participants were asked to describe how their respective mentoring programs affected their performance in the workplace, and the answers were varied. Answers came from both experienced and inexperienced librarians, but all contribute to a better understanding of how mentoring programs can be effective. Many respondents mentioned benefits such as an improved understanding of the institutional culture, the ability to discuss issues of writing and publishing, better goal setting and time management, guidance in the tenure-track process in general, and teaching advice. A number of the benefits described related to improved ability to meet the requirements of tenure, especially those elements of tenure that are "unstated" or informal. Several respondents also said that, as paraprofessional or non-tenuretrack librarians, the mentoring program set them up for success in a professional library position down the road. And, while many participants described how the mentoring program improved performance, some described the mentoring program as having no effect on work performance or even a negative effect for reasons such as poor mentor/mentee pairing, lack of ability to participate, or an unstable mentoring program going through changes.

Participants were also asked to describe specific elements of the program that they found effective or ineffective. More responses were given for how the program was effective, with respondents sharing things like the presence of emotional support, the ability to communicate with another professional and get advice, professional development help, regular meetings, sharing of institutional knowledge, tenure-related help, and proximity of the mentor and mentee (that is to say, how close workspaces were to one another). The consensus from this part of the survey was that having a mentoring program with formalized, regular meetings was a positive aspect for mentors and mentees. However, many respondents also recommended a program that allows for flexibility, and cautioned that the parameters of any mentor/mentee relationship depend on the individuals involved.

The aspects that participants described as ineffective or challenging were issues of time (not having enough time in their own schedules, or not having enough time devoted to the program by the library) and poor matching of mentors and mentees. More than ineffective pairing, respondents warned against a lack of ability in the program to change the pairing should it turn out to be ineffective. A few participants also mentioned that a lack of support from administration can be a significant setback to the effectiveness of a mentoring program. 
Regardless of the participants' mentoring programs, all participants were asked to share what they considered to be elements of an effective mentoring program. Answers ranged from strong help with tenure-related issues, to encouragement and support from the mentor, to help with meeting deadlines. Many respondents thought that a mentoring program with specific activities would be more effective; things like workshops, regular meetings, setting goals and timelines, working together on a project or publication, or job-shadowing programs were mentioned. Not surprisingly, again the responses often centered on help with tenure, some with urgency: "More direct emphasis on portfolio/tenure packet building [is needed.] ... This is a critical, timeconsuming, oft-delayed effort for the tenure-track individual." Again, respondents found that both flexibility (an example: "Some people need a lot of hand-holding, while others prefer to learn on their own...") and structure (for instance: "Sometimes these relationships tend to take a backseat and those involved become out of touch. It needs to be more of a primary responsibility.") were important. These two potentially conflicting ideas were mentioned often, with both being perceived as essential elements of a mentoring program. How flexibility and structure can be effectively balanced in a mentoring program is an issue that was not addressed in the open responses and perhaps requires further study.

A significant portion of the respondents (60\%) indicated that they did not have a mentoring program, formal or informal, at their institutions. Reasons for the absence of a program generally were a lack of support, time, or money, or because of the library's small size or staff. Others explained that their libraries had few new hires or the hires came in with plenty of training and experience, making a mentoring program unnecessary. Some also said that an informal program was present at their library and was considered enough guidance for librarians there. A few respondents expressed frustration that their libraries exhibited a lack of interest in a mentoring program, whether at the administrative or the library staff level. "My library has bigger fish to fry," said one respondent. "No one wants to be responsible for starting one [a mentoring program]. Nobody wants the extra responsibility." The underlying issue in many of these comments seems to be an attitude by library staff or administration that mentoring programs are not worthwhile, or that they must be time-consuming to be effective. Data about the elements of effective mentoring programs could be beneficial to those librarians trying to convince their colleagues of a mentoring program's importance.

\section{Interview Data}

Interviews were conducted with six individuals: two mentoring program facilitators, three mentees, and one mentor. Participants were employed in libraries with a variety of staff sizes, all of which included at least some tenure-track or tenured librarians. When describing the age of their respective mentoring programs, the participants had varied answers, but most described a program that was more than ten years old and had undergone changes or updates in the past 5-7 years. All of the participants described mentoring programs that targeted tenure-track librarians, although a couple of respondents mentioned that their libraries had an additional mentoring program for non-tenure-track librarians and library staff. In almost every interview, the mentoring relationship was described as lasting until the mentee went up for tenure, and many of the activities were directly related to issues of tenure such as working on reappointment papers or meeting tenure requirements.

As with the survey responses, the responses of interviewees about the importance of a formal mentoring program varied. About half of the mentoring programs described were considered formal, while the other three ranged from semiformal to very informal. Most programs involved meetings between the mentor and mentee, but some had a required 
meeting schedule based on the tenure process and others had meeting requirements completely dictated by the mentor/mentee pair. Those programs that described their program activities as more structured and regular seemed to have more positive things to say about their mentoring experiences, but satisfaction with the program did not seem to be correlated to specific mentoring activities or the formality of the program's structure.

However, the advice of interviewees for libraries considering improving or creating a mentoring program showed a couple of distinct themes that supported formal mentoring just as the survey responses did. One was an emphasis on having specific goals or purpose for the mentoring relationship because "it helps people feel like it's a worthwhile investment of their time." Along the same lines, a couple of interviewees warned against treating the relationship like a series of coffee meetings. The meetings should involve some work on both sides and be considered by the mentor as a position of honor that comes with responsibilities.

Several participants suggested that programs could perhaps be enhanced by training of the mentor and/or mentee. One mentee said that mentees might need more guidance "so they can get full use out of [the mentor]," something new librarians might not have experience doing. Another interviewee suggested having the mentor and mentee coauthor or copresent "so you're actually working together on something," resulting in a professional benefit to both mentor and mentee.

Unfortunately, even though there was support for training mentoring participants in interviewee comments, none of the interviewees had a mentoring program that trained its mentors or mentees. The idea of training mentors or mentees was something rarely mentioned in the survey open responses; but, once the interviewers brought it up to the interviewees, the result was a much richer discussion. While librarians might not be thinking of training in their mentoring programs, they seem to be open to the idea when it is introduced. Several described a sort of "check-in" process for mentees or mentors, and one admitted that her library is discussing the idea of training mentors in the future.

The overall impression of the programs by the interviewees was mostly positive, just as the open responses in the survey data were. Mentees appreciated things like having someone to approach with questions, especially "university policies that I don't really understand yet, so I need to ask somebody informally before I even know the right person to email formally." In fact, many of the things mentees appreciated about mentoring relationships matched those described in the survey results as effective elements of mentoring programs, such as help with professional development, advice, and the sharing of institutional knowledge. Facilitators of mentoring programs seemed a little less satisfied, and one described the pushback she sometimes gets from participants as frustrating.

While the mentoring programs of the interviewees varied greatly in their formality, governing structure, and overall success, several elements were consistent between them and the survey results. None of the programs of interviewees had either formal training for mentors or mentees or formal assessment measures. While this might be a significant gap in the structure of the mentoring programs, none of the interviewees seemed to find this a major detriment to the benefits of their programs and no survey respondents singled these elements out as essential to effective mentoring programs. Many of the participants in the interviews and the survey seemed to value structure and specific goals in a mentoring program, regardless of whether they were present in their own programs. Perhaps the most notable trend is that all of the interviewees valued their mentoring programs for the personal benefits they provided, which suggests that library mentoring programs often have positive professional effects for librarians, regardless of whether they are participating as mentees, mentors, or program facilitators. 


\section{Discussion}

After carefully reviewing the responses of the survey and the transcripts of the six interviews, the authors identified six themes in the discussion of effective mentoring programs. These themes both reveal attitudes about mentoring programs in academic librarians and answer our research questions, which are, again:

1. What role does a mentoring program play in preparing novice tenure-track librarians to meet the requirements of tenure?

2. What critical elements define successful mentoring programs for novice tenuretrack librarians in various academic library environments?

\section{Role of Mentoring Programs in Academic Libraries}

\section{Traits of an Effective Mentor}

One issue about which some study participants felt strongly was whether anyone could serve as an effective mentor, or whether an effective mentor possessed certain traits. There was a feeling that in some libraries volunteer mentors are hard to come by, so the only qualification to become a mentor for many of these programs is simply to have an interest in becoming one. One program facilitator said, "I'll see things on the listservs like 'Do you want to be a mentor?' but never is there a thing about what it takes to be a mentor." However, the respondents of the present study made it clear that mentors who had not published or conducted research in a long time, didn't invest in the mentoring relationship, or were unwilling to give constructive feedback did not make good mentors, regardless of their enthusiasm to participate in a mentoring program. Mentoring programs in the literature also describe the frustration of mentees with mentors who "did not necessarily have the time or inclination to provide adequate mentoring," resulting in a relationship that failed to provide the mentee with the guidance he or she needed. ${ }^{34}$

The role of an effective mentor was also discussed thoroughly in the interviews and open responses. Some respondents described a good mentor as someone who is supportive, acts as a friend, and agrees with the mentor about many things. Other respondents valued a supportive mentor but saw the best mentors as those who are not afraid to tell the mentee what he or she doesn't want to hear, have a strong personality, and take the mentoring relationship very seriously (in the capacity of a professional relationship rather than a friend). ${ }^{35}$ Interviewees said things like this:

"The literature really supports someone who is not in a 'go to,' 'what kind of form do I fill out?' kind of role, but really mentoring the person about how not to get yourself into hot water, how do you choose what activities do you want to do."

"If you're going to ask someone to mentor, you have to realize it's not just that you have coffee with them. They have to do some background work or homework."

"It should be more about what people need, not just what would be fun."

The literature may support mentor/mentee relationships that involve "tough love," but the general impression of librarians, especially mentees, seems to be that a mentor is primarily a supporter who makes the mentee feel comfortable. The strongest mentoring programs have mentors who take their role seriously, which often goes hand-in-hand with an institutional attitude that holding a mentor position is a valued and coveted professional responsibility. While often it will come down to the individuals in the mentoring relationship, it seems that a good mentor will both support and provide honest criticism to his or her mentee in an effort to guard him or her from making unwise professional decisions. 


\section{Configuration of Mentoring Programs}

Many of the mentoring programs described by survey and interview participants were traditional one-on-one models. In fact, many of the activities attributed to a mentoring program's effectiveness (regular meetings, working together on a project, having a job shadow program) or ineffectiveness (bad mentor/mentee match, lack of available mentors, small library staff) presume a mentoring program that is made up of mentor-mentee pairs. The literature shows many examples of mentoring programs in academic libraries that do not adopt this model and are able to flourish in spite of some of the challenges mentioned by survey participants. For libraries that lack mentors, a peer-mentoring model might serve them better, allowing for new librarians to share experiences and learn about the institution without being paired with an unmotivated or unavailable mentor. Even libraries with a small staff could use these models or reach out to other nearby campuses and form Communities of Practice. ${ }^{36}$ When there are few new employees but enough qualified mentors, a resource team model could prove effective. It seems that many survey and interview participants perceive the role of a mentoring program at an academic library to be an opportunity for each new employee to meet with one senior library member; when that model is not possible, a mentoring program cannot exist. The literature and some accounts of successful mentoring programs from the open responses and interviews show that the successes of a mentoring program can come from its divergence from the traditional model and its ability to be flexible to the needs of the library staff it serves.

\section{Elements of Effective Mentoring Programs}

One of the issues with mentoring programs that study participants mentioned most frequently was whether or not mentoring programs are more effective when they are mostly either structured or unstructured. Many librarians described their programs as informal but also identified this as a source of dissatisfaction for mentors and mentees. The strongest programs from both the literature and the study participants were described as having clear goals, expectations, and, often, training in how the mentor and/or mentee should contribute to the relationship. Some mentee respondents admitted that with busy schedules they might not be motivated to contribute a lot to the relationship without the structure found in a more formal mentoring program.

Elements of a formal mentoring program as discussed by respondents included orientations or regular meetings just for mentors, a specific number of required meetings for mentors and mentees, or lists of topics or articles to guide discussion for the mentor and mentee. A good number of mentoring programs also included specific elements of the tenure and promotion process in the mentoring program, some in direct conjunction with official evaluations or reappointment-type reviews.

There should be an acknowledgement that many new librarians will create their own informal mentoring relationships with colleagues, especially ones that are in close proximity. These relationships often form regardless of the presence of a formal mentoring program, and many participants described the effects of such a relationship as positive. Perhaps the best program would allow and train for both informal and formal mentoring relationships. ${ }^{37}$

Another issue with a structured mentoring program is that, while it would likely make the mentoring more effective, it would force new librarians who don't want a mentor to participate. Not everyone makes a good mentor, but not everyone makes a good mentee either. At the same time, librarians who seek out mentors might be the kinds of motivated individuals who would succeed with or without a mentor, while those who are reluctant to have a mentor may need guidance most of all. This is an issue perhaps addressed best at the individual library level. 
Comments from survey respondents about their libraries' inability to provide formal mentoring programs because of the unavailability of mentors or mentees show a lack of understanding about nontraditional mentoring models. Peer-mentoring or resource team-mentoring models present alternative models for libraries in need of mentoring options that are more flexible. In fact, some of these models have been adopted by libraries instead of traditional models and were found to be even more successful. ${ }^{38}$

\section{Mentoring Partnerships: Within or Beyond the Library}

The protocol for pairing mentors and mentees ranged in the mentoring programs described in the interviews and survey. Some libraries paired mentees with mentors whose positions were very similar, some went out of their way to pair mentees with mentors who didn't even work in the library, and still others had staff that was too small to be choosy. While out of the scope of this study, mentoring programs through professional organizations allow for even more variety of pairings.

The feedback about mentoring configurations also varied. There were comments that praised programs that paired new librarians with non-librarian faculty and comments that complained about such an arrangement. The literature supports pairing librarians with faculty from a variety of disciplines, but some mentees seem to dislike this arrangement because their mentors cannot answer job-specific questions and are often not in close proximity to answer quick questions. ${ }^{39}$ Proximity is a surprisingly strong factor in the satisfaction of the participants of a mentoring relationship. A good pairing might be as Goldman describes it: "a match with enough similarities to work well together, but enough differences to foster growth." 40

One specific benefit of pairing librarians with faculty outside the library is that it exposes the faculty to interests and priorities of the library, and it creates a campuswide attitude that librarians are of equal status to faculty. One facilitator of a mentoring program said, "I think it's very important for librarians to see themselves, if they are faculty status, as equals.... I have to integrate them, I have to let the other faculty see that they're equal." Librarian-as-educator is a relatively new role, so the affective benefits of pairing librarians with other faculty could be important to helping new librarians embrace this role. At the same time, pairing new tenure-track librarians with faculty outside the library may impede their ability to understand library tenure requirements when they differ from that of other faculty on campus, which, survey results show, is often the case.

Perhaps the best arrangement for a mentoring program (as mentioned earlier), would be a program that allowed for both a structured mentoring relationship, perhaps with someone outside the library department or at least someone with a differing set of job duties within the library, and one or several informal mentoring relationships with colleagues that both have similar job duties and are within close proximity.

\section{Role and Training of Mentors and Mentees}

When asked about how the mentoring program affected the responder's performance in the workplace, the majority of responses from mentors were that because they had mentoring roles they therefore couldn't or didn't need to respond to the question. This seems to suggest an attitude that mentoring is meant to be beneficial to the mentee only and that serving as a mentor is something a librarian does out of kindness, not to gain more professional skills. However, as described below, some of the best mentoring programs have mentors that consider their mentoring role to be a serious, professional one, an essential program element that is found in the literature as well. ${ }^{41}$ This suggests that an attitude by mentors that the mentoring relationship is a mutually beneficial, professional relationship and not just a helpful friendship could lead to stronger mentoring programs. 
A good number of participants questioned whether the mentor and/or mentee should be trained in how to perform their roles, pointing out that such a role may be unfamiliar or unnatural to some. There were a few responses that indicated that mentors or mentees should have training, but no comments from a participant that indicated that his or her library has a program that currently trains mentors or mentees. Despite the positive responses about training, there also was little to no data about what that training would involve. One respondent suggested "training for mentor that clearly outlines how to get started and proceed (schedule regular meetings, ideas for activities, topics of discussion)." While some examples from the literature describe aspects of their mentoring programs that could be considered training, further development in the study of methods of training mentors or mentees could benefit designers and facilitators of mentoring programs.

\section{Mentor/Mentee Relationship}

Many responses indicated that the success of a mentoring relationship depends strongly on the success of the relationship between the mentor and mentee, which, as some pointed out, is very difficult to predict until the mentoring program is already underway. With this in mind, it makes sense that many respondents also thought a good mentoring program would have a way for mentees or mentors to find a new partner as soon as possible instead of being stuck in an uncomfortable, unproductive relationship through the duration of the program. In fact, several of the examples of successful programs from the literature allowed for reassignment or voluntary switching of mentoring groups or pairs.

In examples of mentoring programs discussed by interviewees, sometimes pairswitching involved contacting the coordinator(s) of the program, and sometimes it occurred when one of the members of the relationship was candid with his or her partner about the ineffective pairing and ended the relationship. Some programs attempted to preempt this issue by carefully pairing up mentors and mentees based on their interests and experiences. While this would be a helpful addition to a program, the ability for members of the relationship to be reassigned is still essential.

\section{Conclusion}

Mentoring programs are a great way to help transition new librarians into the world of research, scholarship, and service, especially those novice librarians with tenuretrack responsibilities. The aim of this study is to determine in more detail what type of role mentoring programs play for academic librarians, as well as identify the most important elements leading to their eventual success or failure. While the focus of the study is mentoring programs for tenure-track librarians, many of the conclusions drawn from the data would be applicable to any mentoring program for new academic librarians - or even those in other kinds of libraries. Unlike previous studies of mentoring in specific institutions or studies that provide an overview of mentoring programs for all academic librarians regardless of tenure requirements, this study provides a broad, up-to-date overview of the state of mentoring programs for novice tenure-track librarians that can more easily be applied to libraries of varying sizes, access to resources, and goals.

The survey and interview data collected suggest that participation in mentoring programs involves valuable help with professional, often tenure-related activities on the part of mentees, such as publishing peer-reviewed articles and joining national organizations. Program benefits also included less tangible effects such as increased understanding of institutional culture and improved communication and time management skills, all of which are crucial for librarians pursuing tenure. 
The characteristics of successful mentoring programs found both in the survey and interview results, as well as the literature review, include regular meetings; the ability to switch mentors or mentees easily; dedicated, honest mentors; and clearly stated program goals. Our findings also highlight ways in which mentoring programs can be improved, including providing training for mentors as well as ongoing assessment of the programs, both of which were absent in all mentoring programs studied despite several participants noting that these are important factors. Training and assessment are particularly important due to the fact that there is no easy one-size-fits-all model for a successful mentoring program; the human element is vital, and personal relationships between mentors and mentees rely on numerous factors that must be considered individually and monitored on a continuing basis.

One limitation of this study that should be mentioned was a lack of diversity in the sample due to the decision to only solicit responses from the NMRT and ILI lists. A similar future study might also include CJC-L, COLLIB-L, and ULS-L, among other listservs. The narrow focus of the listservs may also have contributed to a comparatively small number of respondents who identified as novice tenure-track librarians, despite a large overall sample size.

There were also several concepts mentioned by study participants that, while outside the scope of this study, invite further research. First, our findings suggested that both a formal structure and a level of flexibility were cited as essential elements of a mentoring program, and how to best achieve balance between these apparently conflicting ideas of formality and informality could be an area of future inquiry. In addition, a good number of respondents expressed dissatisfaction with their professional support. This is not just because there was an absence of a mentoring program, but rather because the training program of their libraries was inadequate. Illuminating the elements of a strong library training program could be another avenue of further research. While some of the questions in the survey addressed instruction and mentoring, there was very little feedback from respondents about how instruction fits into mentoring programs or about how new teaching librarians receive informal or on-the-job training. Examining this area in more detail could lead to a set of standards for the mentoring and training of new instruction librarians, a library staff role that is continuing to involve more librarians. Finally, several responses suggested a common misperception that mentoring programs are intended solely to benefit the mentee. Additional research on how such programs can be beneficial to the mentor could serve as further motivation to those libraries hesitant to invest resources into starting a mentoring program.

The present study is significant due to the fact that 60 percent of librarians surveyed did not have a mentoring program in place at their institutions, and a prevalent comment was that LIS programs are not doing an adequate job of exposing students to the realities of tenure-track positions. The benefits reported by mentees suggest significant value resulting from the implementation of a mentoring program, and the findings on effective program elements and areas needing improvement will provide practical guidance to academic libraries considering starting a mentoring program or improving an existing one. 


\section{Appendix A. Survey Questions}

\section{Introductory Questions}

1. What kind of librarian are you?
$\square$ Academic
$\square$ School
$\square$ Public
$\square$ Special
$\square \quad$ Special Collections/Archives
$\square$ Student

2. Which of the following are you?
$\square \quad$ library school student
$\square$ library school graduate
$\square$ newly hired librarian (first professional library position)
$\square$ newly hired librarian (have professional experience at another library)
$\square$ librarian with 2 or more years at current institution
$\square$ retired librarian

\section{Tenure-Track}

3. Are you a tenure-track or tenured librarian?
$\square \quad$ Neither
$\square \quad$ Tenure-track
$\square$ Tenured

4. If you are a tenure-track or tenured librarian, is this your first tenure-track position?
$\square \quad$ Yes
$\square \quad$ No
$\square \quad$ N/A

5. If you are a tenure-track librarian, what are the requirements for tenure at your institution?

6. Before your current position, how many times had you done the following?
$\square \quad$ Published a peer-reviewed article
$\square$ Published a non-peer-reviewed article
$\square \quad$ Written a blog/review/opinion piece
$\square \quad$ Taken a research methods course
$\square$ Had training in instruction
$\square$ Taught
$\square \quad$ Served on committees
$\square$ Been involved in professional organizations at the national level
$\square$ Presented at a conference

\section{Mentoring Program}

7. Does your library currently have a formal or informal mentoring program beyond new librarian training? If no, skip to question 18.

$\square \quad$ Yes

8. Have you participated in the mentoring program? If no, skip to question 18.
$\square \quad$ Yes
$\square \quad$ No 
9. Which of the following were/are you?

Mentor

Mentee

$\square \quad$ Facilitator

10. What areas does the mentoring program attempt to address?
$\square \quad$ Publishing
$\square$ Research
$\square \quad$ IRB procedures
$\square \quad$ Writing skills
$\square \quad$ Committee work
$\square \quad$ Presenting at conferences
$\square \quad$ Professional organization involvement
$\square \quad$ Institutional culture
$\square \quad$ Writing grants
$\square \quad$ Promotion and tenure
$\square \quad$ Other (please list)

11. What activities does the mentoring program include?
$\square \quad$ Regular meetings
$\square \quad$ Panel presentations
$\square$ Workshops
$\square \quad$ Cooperative projects
$\square \quad$ Suggested readings
$\square$ Open communication
$\square \quad$ Critical friend relationship
$\square$ Website/social media
$\square \quad$ Other (please list)

12. After participating in the mentor program how many times have you done the following?

$\square$ Published a peer-reviewed article

$\square$ Published a non-peer-reviewed article

$\square \quad$ Written a blog/review/opinion piece

$\square \quad$ Taken a research methods course

$\square$ Had training in instruction

$\square \quad$ Taught

$\square$ Served on committees

$\square$ Been involved in professional organizations at the national level

$\square$ Presented at a conference

13. How has the mentoring program affected your performance in the workplace?

14. How has the mentoring program affected your ability to meet tenure-track requirements?

15. What elements of the mentoring program, if any, are most effective? Why?

16. What elements of the mentoring program, if any, are not effective? Why?

17. In your opinion, what would the ideal mentoring program for tenure-track librarians look like?

18. If your library doesn't have a mentoring program for new tenure-track librarians, why not?

19. If you would be willing to be contacted for an interview, please provide your email address below. Thank you! 


\section{Appendix B. Interview Questions}

\section{Background Questions}

1. Please describe your library.

a. How many staff members does the library have?

b. How many of those staff members are tenure-track librarians?

c. How many students do you serve?

d. What is your position at the library?

e. How long have you worked at this library?

f. How many new librarians has your library hired in the past 5 years?

2. What are the requirements for tenure at your institution?

a. Are the requirements different for librarians? (vs. other faculty)

\section{Mentoring Program Questions}

3. When was the program created?
a. Has the program undergone any significant changes since that time?

4. Why was the program created?
a. Who was the creator?

5. What is your role in the mentoring program?

a. Had you experienced other mentoring programs before this one?

6. Does your library mentoring program target tenure-track librarians?

a. Why or why not?

7. What are the goals of the program?

8. Is the program more formal or informal?

a. What influenced your decision to make the program formal/informal?

9. What kind of administrative support did/do you have?

a. Has the amount of support changed over time?

b. What kind of support did/do you have among the participants? Staff who are not qualified to participate?

10. Who facilitates the program? Is it a person, group, committee, etc.?

11. Who is eligible to participate in the program?

a. What factors influenced your eligibility decisions?

12. How are participants selected?

a. Are there any library staff members who would like to be participants but can't be?

b. What influenced your decision to select participants this way?

13. How long does the program last?

a. Does the mentor-mentee relationship ever continue beyond the formal program length?

14. Is there mentor training involved in the program?

a. Why or why not?

b. What does the training consist of?

15. What assessment measures are in place for the program?

a. What elements of the program are assessed?

b. How are the mentee and mentor involved in assessment?

16. What specific activities are involved in the program?

a. What prompted you to choose these activities?

17. Have you encountered any limitations or barriers in the creation/implementation of this mentoring program?

a. How did you overcome them? 
18. What feedback have you received from participants?

19. What is your overall impression of the mentoring program's success or failure?

20. Do you have any specific recommendations for libraries considering starting a mentoring program?

\section{Additional Follow-Up Questions}

1. What do participants think of the time commitment?

2. What is the cost of the program?

3. What research did you (or the program's creator) do before beginning to implement the program?

4. Are there elements of a mentoring program that could be taught in library school before the employee starts a professional position?

5. Do you perceive any difference in the way librarians are prepared for promotion and tenure and the way other faculty are prepared?

6. What does the program do to address scholarship? Service? Teaching?

7. How much experience with scholarship, service, and tenure do new librarians tend to have upon arrival at your library?

\section{Notes}

1. Shin Freedman, "Effective Mentoring," IFLA Journal 35, no. 2 (2009): 171-82.

2. Eamon C. Tewell, "Employment Opportunities for New Academic Librarians: Assessing the Availability of Entry Level Jobs," portal: Libraries and the Academy 12, no. 4 (2009): 407-23.

3. Sarah J. Fletcher and Carol A. Mullen, The Sage Handbook of Mentoring and Coaching in Education (Los Angeles: Sage, 2012), 7.

4. Bonnie A. Osif, "Successful Mentoring Programs: Examples from within and without the Academy," Journal of Business \& Finance Librarianship 13, no. 3 (2008): 335-47.

5. Kathy E. Kram, Mentoring at Work: Developmental Relationships in Organizational Life, (Lanham, Md.: University Press of America, 1988).

6. Ibid., 60 .

7. Ibid.

8. Freedman, "Effective Mentoring," 173.

9. Nikhat Ghouse and Jennifer Church-Duran, "And Mentoring for All: The KU Libraries' Experience," portal: Libraries and the Academy 8, no. 4 (2008): 373-86.

10. Eileen K. Bosch, Hema Ramachandran, Susan Luévano, and Eileen Wakiji, "The Resource Team Model: An Innovative Mentoring Program for Academic Librarians," New Review of Academic Librarianship 16, no. 1 (2010): 58.

11. Ghouse and Church-Duran, "And Mentoring for All," 376.

12. Ibid., 379.

13. Freedman, "Effective Mentoring," 173.

14. Ibid.

15. Kathy E. Kram, "Phases of the Mentor Relationship," Academy of Management Journal 26, no. 4 (1983): 608-25.

16. Freedman, "Effective Mentoring," 176.

17. Ghouse and Church-Duran, "And Mentoring for All," 375.

18. Harrington, Marni R. and Elizabeth Marshall, "Analyses of Mentoring Expectations, Activities, and Support in Canadian Academic Libraries," College \& Research Libraries, 75, no. 6 (2014): 763-790.

19. Freedman, "Effective Mentoring," 176.

20. Osif, "Successful Mentoring Programs," 335.

21. Maria K. Lee, Mentoring in the Library: Building for the Future (Chicago, Ill.: American Library Association, 2011).

22. Ibid., 60 .

23. Ibid., 61.

24. Bosch, Ramachandran, Luévano, and Wakiji, "The Resource Team Model," 57-74.

25. Ibid., 60.

26. Susan P. Lieberthal, “Perspectives on Peer Support for Tenure-track Librarians: The Annual 
'Juniors' Retreat at Stony Brook University,' Collaborative Librarianship 1, no. 2 (2009): 30-47.

27. Ibid., 32.

28. Ghouse and Church-Duran, "And Mentoring for All," 375.

29. Molly Keener, Vicki Johnson, and Bobbie L. Collins, "In-house Collaborative Mentoring," CERL News 73, no. 3 (2012): 134-36; Jill Cirasella and Maura A. Smale, "Peers Don't Let Peers Perish: Encouraging Research and Scholarship Among Junior Library Faculty," Collaborative Librarianship 3, no. 2 (2011): 98-102.

30. Keener, Johnson, and Collins, "In-house Collaborative Mentoring."

31. Kristin J. Henrich and Ramirose Attebury, "Communities of Practice at an Academic Library: A New Approach to Mentoring at the University of Idaho," Journal of Academic Librarianship 36, no. 2 (2010): 158-65.

32. Bosch, Ramachandran, Luévano, and Wakiji, “The Resource Team Model," 57.

33. Ghouse and Church-Duran, "And Mentoring for All."

34. Diana Farmer, Marcia Stockham, and Alice Trussell, "Revitalizing a Mentoring Program for Academic Librarians," College \& Research Libraries 70, no. 1 (2009): 8-24.

35. Keener, Johnson, and Collins, "In-house Collaborative Mentoring."

36. Henrich and Attebury, "Communities of Practice at an Academic Library."

37. Crystal Goldman, "First-Year Library Mentorship Opportunities," Urban Library Journal 17, no. 1 (2011).

38. Farmer, Stockham, and Trussell, "Revitalizing a Mentoring Program for Academic Librarians."

39. Henrich and Attebury, "Communities of Practice at an Academic Library."

40. Goldman, "First-Year Library Mentorship Opportunities."

41. Elizabeth M. Doolittle, J.B. Graham, A. Martin, H. Mendelsohn, K. Snowden, and A. Stone, "Creating a Culture of Mentoring @ Your Library," Southeastern Librarian 57, no. 1 (2009): 29-37.

42. Ghouse and Church-Duran, "And Mentoring for All." 